\title{
Sternal Neoplasm
}

National Cancer Institute

\section{Source}

National Cancer Institute. Sternal Neoplasm. NCI Thesaurus. Code C6730.

A benign or malignant neoplasm that affects the sternum. 